\title{
Corking the Chunnel
}

from Angela Croome

THere have been complaints that the cancellation of the British-French Channel Tunnel Project last week by Anthony Crosland, Secretary of State for the Environment, was both hasty and premature. But this seems a point of view that is difficult to justify for a scheme that has been in the pipeline (as it were) for well over a hundred years. Indeed, a look at the 'on/off' history of this latest Chunnel plan (going back to the 1962 White Paper Proposals for a Fixed Channel Link) it is remarkable that the scheme survived the rejection in 1968 by both the British and French governments of the industrial proposals they had called for the year before. Rather than projecting an image of the 'white heat of technology', which was the watchword of the then Wilson government, the plan always had a gaslit and fustian air about it.

Tunnelling was above all a nineteenth century enthusiasm. It was indeed a technological innovation then-an extension of the techniques used in mining deeper and in some cases (as in Cornwall) under the sea. The Cornish engineer, Richard Trevithick, was called in to complete the first Thames tunnel (between Rotherhithe and Limehouse) in the early $1880 \mathrm{~s}$. With the aid of picked gangs of stout Cornish miners accustomed to working in a crouched position and in unbelievably horrible conditions he would certainly have succeeded had the money not finally run out only 200 feet from the far end. There is no trace of Trevithick's tunnel today. It took the Brunels, father and son, another 40 years to bring off the first Rotherhithe tunnel for wheeled traffic (now used by the London Underground). There were several cave-ins and a number of miners also died from the "tunnel disease"-a lung complaint attributed to the poisonous air in the workings. Many technological advances were made in completing "The Thames Tunnel" as the Brunel venture came to be called, including the special shield designed by Isambard Kingdom Brunel on the system of the burrowing shipworm Teredo navalis to hold the newly bored walls in place until lining was completed. But bridges increasingly superseded tunnels as a traffic link as the century progressed. And it is hard to see that there is any comparison at all in convenience, flexibility and 'passenger satisfaction'. The prospect of travelling not merely underground but underwater for the best part of an hour is a nightmarish prospect for many people.

Despite the long gestation period of

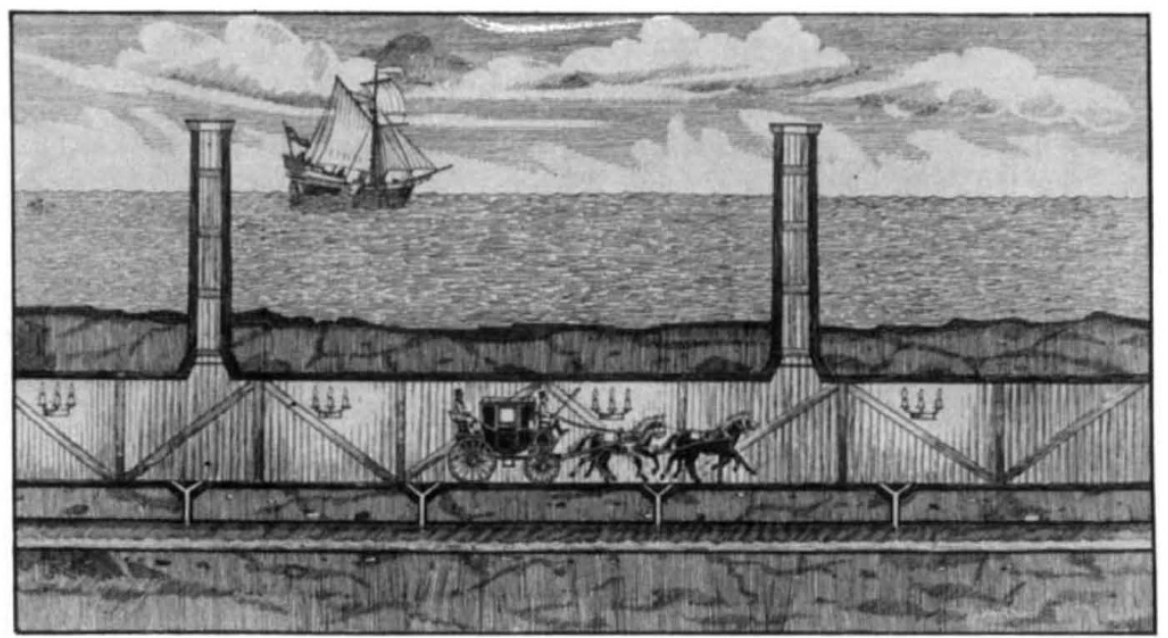

To Paris by carriage (with a gaslit and fustian air).

the Chunnel scheme, and the various assessments and reappraisals, the Cairncross review, the revised rail-link proposals and so forth, there has never been the sense of a real solution to the cross-channel traffic problem but rather a look of amateurish gimmickry. Has a serious study ever been made of a cross-channel bridge? Would it really be more vulnerable than a tunnel? Some years ago Desmond King-Hele put forward the virtues of a channel dam-and not entirely as a jeu d'esprit.

France is better linked to Britain than is any other European country. Nor can there be any question that another link with the capacity of the present channel ferries concentrated into the south-east tip of Britain would increase the congestion of the most crowded part of the country. There is considerable resentment already-in Belgium for instance-that so much freight has to be routed through France, picking up an additional and particularly swingeing tariff on the way. This has also put up the price of the goods in Britain.

There seems an excellent case for new links to the continent from the east coast of Britain and the more westerly of the south coast ports, thus better distributing traffic and avoiding the London bottleneck, and also bringing welcome growth to the less industrialised regions. This need not be motorised traffic either-whole trains travel by ferry in Scandinavia. The south coast port authorities have already indicated that they could handle twice the present traffic, which corresponds closely with the amount predicted for the tunnel at its planned opening date in 1981.

The potential of the hovercraft link seems to have been ignored in the predictions and calculations. Yet this type of ferry (using the current SRN-4, a 350 -ton vehicle) takes only 30 minutes to cross the same route as the pro- jected Chunnel, the journey in which was expected to last nearer an hour. Five craft now carry $25 \%$ of all passenger traffic on this route. Docking requirements, and therefore land use, is minimal. Apart from their rapidity, they perhaps represent the most flexible type of sea link yet devised. It is paradoxical that while the French have felt obliged to cry "perfidious Albion" again over Crosland's tunnel decision the partly state-subsidised Bertin company is hurrying to complete a larger cross-channel hover-ferry, the Naviplane 500, which is expected to be at the trials stage in 1976 and no doubt in competition with the British service shortly after. That there are no plans to develop a larger version of the SRN-4, nor a successor, is a matter of major concern in the industry.

Which brings one back to the lack of a true overall plan for traffic and transport development in Britain. What happened to the comprehensive independent study commissioned by the Ministry of Technology in the mid1960s?

There is no reason to doubt that modern technology could build a channel tunnel if the nation was prepared to spend enough on it. If a prestige gesture for a technologically advanced (and united) Europe is a worthy object, then a Wilson-D'Estaing bridge would be much more telling than a MacmillanDe Gaulle tube. If better communications and a good return for money is the point, then the Secretary of State for the Environment has done the right thing and not a moment too soon, though it will be important to follow up a sensible saving with a sensitive alternative solution or solutions. The one bit of advanced technology that one must regret will not now come to fruition is the project of certain citizens of Kent for a Great Channel Tunnel Cork-to plug the great channel tunnel's mouth when it was finished 